\title{
O ENSINO DE SOLOS NOS DIFERENTES NÍVEIS DE EDUCAÇÃO EM GEOGRAFIA ${ }^{1}$
}

\author{
Soil education at different levels of education in Geography
}

Luis Eduardo Akiyoshi Sanches Suzuki Professor Doutor da Universidade Federal de Pelotas dusuzuki@email.com

Liz Cristiane Dias Professora Doutora da Universidade Federal de Pelotas liz.dias@yahoo.com.br

Moisés Ortemar Rehbein Professor Doutor da Universidade Federal de Pelotas moisesgeoufpel@gmail.com

Edvania Aparecida Corrêa Professora Doutora da Universidade Federal de Pelotas edvania.correa86@gmail.com

\author{
Recebido em 25/05/2020 \\ Aceito em 01/06/2020
}

RESUMO: Este trabalho pretende trazer para discussão as diferentes abordagens da Ciência do Solo no ensino da Geografia, buscando auxiliar seu ensino nos cursos de Licenciatura em Geografia. Os objetivos deste trabalho são: 1) verificar os eixos temáticos relacionados à Ciência do Solo no ensino de Geografia no nível fundamental e médio, a partir dos PCNs e livros didáticos; 2) avaliar o conhecimento em Ciência do Solo dos alunos do curso de Licenciatura em Geografia da UFPel; 3) realizar um levantamento das universidades no Rio Grande do Sul que possuem cursos de Geografia e, para estes cursos, fazer uma caracterização das disciplinas da área de Ciência do Solo. A partir deste estudo pode-se constatar que os PCNs para a Geografia e os livros didáticos para o ensino fundamental e médio abordam de forma pouco abrangente o conhecimento sobre solos. Poucos cursos de Licenciatura em Geografia possuem em seu currículo disciplinas na área de Ciência do Solo, havendo a necessidade de reformulação de seus projetos pedagógicos quanto à inserção de disciplinas relacionadas à área da Ciência do Solo.

Palavras-chave: Educação em solos; Parâmetros Curriculares Nacionais; Ciência do solo; Formação de professores; Projeto pedagógico.

ABSTRACT: This work intends to bring to discussion the different approaches of Soil Science in the teaching of Geography, seeking to assist its teaching in the Geography courses. The objectives of this work are: 1) to verify the thematic axes related to Soil Science in the teaching of Geography at the elementary and medium school level, based on "PCNs" and textbooks; 2) to evaluate the knowledge in Soil Science of the students of the Geography course at UFPel; 3) carry out a survey of universities in Rio Grande do Sul state that have Geography courses and, for these courses, characterize the disciplines in the field of Soil Science. From this study it may be seen that the "PCNs" for Geography and textbooks for elementary and medium school level have a restrict approach to knowledge about

\footnotetext{
${ }^{1}$ Este trabalho é parte do Trabalho de Conclusão de Curso do primeiro autor, intitulado "Ensino de solos nos diferentes níveis de educação em Geografia: O conhecimento de solos dos estudantes de graduação em Geografia da UFPel", apresentado no ano de 2017 ao curso de Licenciatura em Geografia da Universidade Federal de Pelotas (UFPel).
}

REVISTA GEONORTE, V.11, N.37, p.01-21, 2020. 
soils. Few Geography courses have disciplines in the field of Soil Science in their curriculum, with the need to reformulate their pedagogical projects regarding the insertion of disciplines related to the field of Soil Science.

Keywords: Soil education; National Curriculum Parameters; Soil science; Teacher training; Pedagogical project.

\section{INTRODUÇÃO}

O ensino de solos na Geografia é importante pois, a partir do seu conhecimento, podese fazer associações e inferências sobre diversos assuntos geográficos, além da importância de conscientização do cidadão dos processos essenciais exercidos pelo solo para manutenção da vida na Terra.

É preciso entender que os problemas ambientais, tanto em áreas urbanas quanto em áreas rurais, são resultados das relações que se estabelecem entre os fatores físiconaturais e a sociedade.

\footnotetext{
"Daí a opção por pensar as temáticas físico-naturais do espaço geográfico para além da somatória das análises físico-naturais e sociais. É preciso compreender como esses aspectos se articulam ao se empreender uma análise mais integrada do espaço geográfico. É este o papel que a Geografia deve cumprir na escola: favorecer a formação de cidadãos críticos e conscientes de sua atuação na realidade em que vive." (MORAIS, 2011, p. 18).
}

O conceito de solo varia de acordo com o ponto de vista de quem o define. Por exemplo, para os profissionais do ramo da agricultura, o solo é visto como uma fonte de renda, pois o solo irá servir de suporte para as plantas. Para alguns profissionais da Engenharia, o solo serve de substrato para a construção de estradas, prédios etc. e, para os profissionais da mineração, o solo dificulta que seja alcançada certa riqueza mineral que se encontra sob ele. Já para as crianças do Ensino Fundamental, o conceito de solo é muito abstrato, pois muitas vezes elas não têm contato algum com o solo no seu dia a dia, principalmente em áreas urbanizadas e impermeabilizadas (OLIVEIRA, 2014).

Vaz e Anjos (2009) apontaram algumas áreas do conhecimento que estudam o solo sob diferentes pontos de vista, dentre elas, os autores citam: Engenharia Sanitária, Engenharia Civil, Engenharia Florestal, Agronomia, Geografia, Zootecnia, Biologia, Geologia. Contudo, Silva e Ribeiro (2004) verificaram que existe uma grande lacuna no ensino de solos ministrados nos cursos de graduação e isto é mais evidente nos cursos de Geografia do Programa de Capacitação de Docentes (PROCAD) de algumas cidades Maranhenses. O PROCAD é um programa do Governo Federal que visa a qualificação de professores seja em nível de graduação ou pós-graduação. Ainda de acordo com os autores, de modo geral, os alunos não têm acesso a informações corretas e atualizadas sobre solos.

De acordo com Sacramento e Falconi (2011) o solo nas escolas públicas ainda é pouco ou quase nada estudado, gerando a falta de conhecimento de um elemento essencial do espaço geográfico. Mesmo com trabalhos em algumas universidades, 
com grupos de pesquisa sobre o ensino de solos, de dissertações e teses que destacam o assunto, há pouco desenvolvimento nas salas de aula abordando o solo.

Embora este tema seja abordado nos Parâmetros Curriculares Nacionais (PCNs) e nos currículos escolares, ele apresenta problemas devido a falhas nos livros didáticos e na formação básica e continuada dos professores (LIMA, 2005).

Nesse sentido, analisando alguns livros didáticos de Geografia, Silva, Falcão e Sobrinho (2008) identificaram que os livros didáticos apresentam o solo na disciplina de Geografia no ensino fundamental II. No entanto, a abordagem trazida por esses livros não proporciona o seu entendimento como um elemento natural componente da paisagem e resultante de processos geomorfológicos, climas, material de origem, organismos vivos e tempo de formação.

Da mesma forma, com o objetivo de conhecer como o conteúdo solo é abordado nos livros didáticos de Geografia do $6^{\circ}$ ao $9^{\circ}$ ano do ensino fundamental da rede estadual e municipal de ensino da cidade de Goiás/GO, Costa e Mesquita (2010) verificaram que a forma como o conteúdo é trabalhado nos livros didáticos contribui para que os alunos tenham uma percepção errônea do solo enquanto recurso e, sobretudo, deixam de reconhecer a sua importância enquanto elemento da paisagem. Além disso, as metodologias adotadas pelo professor em sala de aula, na maioria das vezes, não despertam a atenção dos alunos e não promovem seu aprendizado.

Os livros didáticos apresentam conceitos muito superficiais sobre solos, desatualizados e incorretos, pois a deficiência também ocorre na formação dos professores e autores de livros didáticos sobre o tema solo (OLIVEIRA, 2014).

Considerando as limitações de muitos livros didáticos sobre o conteúdo solos, as universidades possuem importante papel na produção de material que possa ser utilizado por professores dos ciclos fundamentais. No entanto, este material deve ser claro e acessível, visualizando o tema "solo" como um conteúdo transversal, e estabelecendo sua relação principalmente com as Ciências Naturais e a Geografia, com linguagem acessível e ao mesmo tempo correta tecnicamente, além de compatíveis com os PCNs (SILVA; RIBEIRO, 2004).

Isto também pode ser realizado a partir da redefinição do processo de formação de professores. As universidades podem contribuir através de cursos e eventos de educação continuada, elaboração de publicações, desenvolvimento de experiências, organização de exposições didáticas, e disponibilização de informações por meio da internet, dentre outras atividades (LIMA, 2005).

Pretende-se trazer com este trabalho uma discussão sobre as diferentes abordagens da Ciência do Solo nos distintos níveis de ensino (Fundamental, Médio e Graduação), buscando subsídios para auxiliar o ensino de Ciência do Solo nos cursos de graduação em Geografia, especialmente a Licenciatura. Para tanto, os objetivos específicos deste trabalho são: 1) verificar os eixos temáticos relacionados à Ciência do Solo no ensino de Geografia no nível fundamental e médio, a partir dos PCNs para a Geografia e em livros didáticos; 2) avaliar o conhecimento em Ciência do Solo dos alunos do curso de Licenciatura em Geografia da Universidade Federal de Pelotas (UFPel), e a percepção deles sobre a abordagem do assunto no curso; 3) realizar um 
levantamento das universidades públicas e particulares no Rio Grande do Sul que possuem curso de Licenciatura e/ou Bacharelado em Geografia e, para estes cursos, fazer uma caracterização das disciplinas ligadas à área de Ciência do Solo.

\section{MATERIAIS E MÉTODOS}

Este trabalho contempla uma pesquisa documental (SEVERINO, 2007), tendo como fonte de pesquisa os PCNs (BRASIL, 1998), os livros didáticos, a internet, os projetos pedagógicos e os planos de ensino e/ou ementas de disciplinas da área de Ciência do Solo de cursos de graduação em Geografia.

Também se utiliza como técnica de pesquisa um questionário com questões abertas que, de acordo com Severino (2007) é um conjunto de questões sistematizadas, com o objetivo de obter informações por parte dos pesquisados, onde eles elaborarão suas respostas com suas próprias palavras.

Os livros didáticos de Geografia utilizados são do Projeto Araribá para o $6^{\circ}$ (DANELLI, 2007a), $7^{\circ}$ (DANELLI, 2007b), $8^{\circ}$ (DANELLI, 2007c) e $9^{\circ}$ (DANELLI, 2007d) ano do ensino fundamental, referente ao Programa Nacional do Livro Didático (PNLD) de 2011 a 2013 e do PNLD de 2014 a 2016 (VEDOVATE, 2010a, b, c, d). Utiliza-se também o livro "Geografia: O mundo em transição", para o ensino médio, de VESENTINI (2010).

A partir dos PCNs para a Geografia e dos livros didáticos, foram elencados os assuntos abordados no ensino fundamental e médio relacionados à Ciência do Solo. A partir destes assuntos, elaborou-se um questionário (Quadro 01) incluindo questões sobre solos, o qual foi aplicado aos alunos em fase de conclusão do curso de Licenciatura em Geografia da UFPel. Os alunos não foram identificados nos questionários. 
Quadro 01. Questionário aplicado aos alunos do curso de graduação em Geografia (Licenciatura) da Universidade Federal de Pelotas.

\section{UNIVERSIDADE FEDERAL DE PELOTAS Instituto de Ciências Humanas Licenciatura em Geografia}

Por favor, seja breve e sucinto em suas respostas.

\section{Identificação}

Idade:

Sexo:

Ano de ingresso no curso:

\section{Questões técnicas}

1) O que é solo?

2) Como ocorre a formação do solo?

3) O que é erosão?

4) O que é plantio direto, cultivo mínimo e plantio convencional?

5) O que é terraceamento e curva de nível?

6) O que é perfil de solo? E horizontes do solo?

7) Você cursou alguma(s) disciplina(s) específica(s) sobre solos em seu curso? Caso afirmativo, aponte-a(s).

8) Independente se o curso possui ou não disciplina de solos no currículo, qual a importância da(s) disciplina(s) de solos na sua formação?

9) Você se sente preparado para trabalhar com o tema Ciência do Solo?

10) Caso não esteja preparado para trabalhar com o tema Ciência do Solo, o que você entende que seria necessário no curso para prepará-lo para esta área?

Agradecemos sua colaboração no preenchimento deste questionário. Salientamos que seu nome será preservado, não sendo citado durante a pesquisa.

\section{Org: Autores}

Os questionários foram aplicados em dois momentos: em novembro de 2015, aos alunos do oitavo semestre (alunos formandos), e em junho de 2016, aos alunos do sétimo semestre. Sua proposta foi avaliar se o conhecimento em Ciência do Solo dos alunos do curso de Licenciatura em Geografia da UFPel atende os PCNs e aos livros didáticos. A partir das respostas, os dados foram tabulados e analisados de forma descritiva.

Em outra etapa do trabalho, foi feito um levantamento, pela internet, de universidades públicas e particulares no Rio Grande do Sul que possuem curso de Geografia, seja Licenciatura e/ou Bacharelado. A partir da identificação das instituições que possuem curso de Geografia, foi feita uma busca do projeto pedagógico do curso e de planos de ensino e/ou ementas de disciplinas da área de Ciência do Solo disponíveis na internet, com o intuito de caracterizar o nome da(s) disciplina(s) relacionada(s) à Ciência do Solo, a carga horária, o semestre em que ela é ministrada, se é da Licenciatura ou Bacharelado e o conteúdo abordado na(s) disciplina(s). 


\section{RESULTADOS E DISCUSSÕES}

\section{Eixos temáticos em Ciência do Solo nos PCNs e nos livros didáticos}

Os PCNs para o terceiro ( $5^{\mathrm{a}}$ e $6^{\mathrm{a}}$ série) e quarto ciclo ( $7^{\mathrm{a}}$ e $8^{\mathrm{a}}$ série) indicam como tema transversal "meio ambiente" (BRASIL, 1998). Nestes, o tema Sociedade e Meio Ambiente trata da formação socioespacial, das novas territorialidades e temporalidades do mundo além de abordar de forma ampla os processos que geram uma determinada ocupação do solo, as demandas por recursos naturais, o crescimento populacional e a urbanização, entre outros. Compreende também as relações com as diferentes paisagens vegetais e a zonalidade dos tipos de solos e trata dos componentes da natureza nas suas especificidades, mas sem perder de vista que muitos dos seus mecanismos são interativos.

Considerando o exposto, o ensino de solos pode ser abordado dentro do tema transversal "meio ambiente", buscando relacionar o clima e a vegetação, os solos e o relevo, ou ainda como clima, solos e relevo se inter-relacionam. Pode-se também trabalhar como determinados tipos de solos reagem aos modos de ocupação, ou ainda, discutir como ocorre a erosão, a desertificação, os deslizamentos de terra e suas relações com o desmatamento, a irrigação ou o uso excessivo dos solos.

Sobre o conteúdo desenvolvido no livro de Geografia do Projeto Araribá para o 60 ano do ensino fundamental (DANELLI, 2007a), referente ao PNLD de 2011 a 2013, verificou-se o seguinte:

- Unidade 1 (A Geografia e a compreensão do mundo): no tema 1 (Paisagem, espaço e lugar) a abordagem do solo pode ser qualificada e aprofundada, bem como utilizar termos mais adequados, quando se fala sobre a "destruição da vegetação" e "exploração do solo" no item "as paisagens transformadas". Pode-se utilizar termos técnicos associados aqueles utilizados no livro, como por exemplo: "lavar" os nutrientes do solo pode ser substituído por "lixiviar" e/ou "escoar"; "detritos" (fragmentos de rochas, solo) pode ser substituído por sedimentos. No tema 2 (O trabalho e a transformação do espaço geográfico) o solo pode ser abordado diretamente e intensamente, pois a divisão territorial do trabalho e as relações entre trabalho e paisagem envolvem o solo.

- Unidade 4 (Relevo e hidrografia): no tema 2 (Os processos de formação e transformação do relevo), quando se fala sobre erosão, especialmente a acelerada, a pluvial e a eólica, o solo pode ser abordado diretamente, especialmente as fases do processo erosivo e de que forma a ação do homem pode influenciar neste processo. Até mesmo quando se fala sobre relevo, as características do solo, que muitas vezes definem seu uso, sofrem influência do relevo.

- Unidade 6 (O campo e a cidade): o solo pode ser abordado de forma intensa no tema 1 (O espaço rural e suas paisagens), relacionando o solo com a tecnologia empregada, tamanho da propriedade rural e tipo de cultivo; no tema 2 (Problemas ambientais no campo), quando se fala sobre a degradação dos solos; uso de fertilizantes químicos e agrotóxicos e contaminação do solo e da água; impactos ambientais resultantes da irrigação. 
- Unidade 7 (Extrativismo e agropecuária): no tema 3 (A agricultura) o solo também pode ser abordado de forma intensa e direta, quando se fala sobre as "condições naturais necessárias para o desenvolvimento da agricultura" e os "tipos de agricultura" (subsistência e comercial). Percebe-se que no conteúdo para 060 ano 0 conhecimento sobre o solo é essencial, e um conhecimento mais aprofundado permite fazer relações que possibilitam um olhar mais abrangente sobre o espaço geográfico.

Corroborando com estas observações, Oliveira (2014) verificou que os conceitos apresentados nos livros didáticos são muito superficiais, desatualizados e incorretos, e essa deficiência também ocorre na formação dos professores e autores de livros didáticos sobre o tema solo. Lima (2005) também cita que apesar da importância do solo para o ser humano, o ensino deste tema na educação fundamental pode ser considerado de qualidade inferior à desejada, devido a um conjunto de fatores educacionais, sociais e econômicos, enquanto que o conteúdo solos, embora abordado nos PCNs e nos currículos escolares, apresenta problemas em sua implantação, por causa de falhas nos livros didáticos e na formação básica e continuada dos professores.

A respeito do conteúdo abordado no livro de Geografia do Projeto Araribá para o $7^{\circ}$ ano do ensino fundamental (DANELLI, 2007b), referente ao PNLD de 2011 a 2013, observou-se o seguinte:

- Unidade 3 (Industrialização e urbanização do Brasil): no tema 4 (Problemas sociais e ambientais nas cidades) há um pequeno apontamento sobre a ocupação de casas em áreas de risco, como vertentes de morros ou às margens de rios. Nesse caso, a discussão pode ser intensificada a respeito de deslizamentos associados a solos rasos nas encostas; o assoreamento de rios devido ao solapamentos de taludes, intensificando o aporte de sedimentos na calha fluvial e possibilitando inundações de maiores abrangências e recorrências; mantos de alteração espessos e de abruptos contatos líticos, que favoreçam o escoamento em encostas de declividades acentuadas; remoção da vegetação natural e a realização de cortes e aterros no terreno para instalação de construções, sem o devido cuidado geotécnico, o que costuma desestabilizar o material na encosta. O livro ainda aborda as regiões do Brasil (Norte, Nordeste, Sudeste, Sul, Centro-Oeste), e nelas ressalta-se a questão agrícola, o povoamento, a ocupação do espaço, problemas com erosão, mas pouco se associa o solo nestas questões. Na região Norte o livro aponta sobre "a importância da floresta Amazônica" e cita que seus solos são bastante pobres em nutrientes, mas como a floresta é muito densa, forma-se sobre o solo uma camada de folhas, galhos e troncos, que se decompõem formando os nutrientes necessários para a manutenção da floresta. Neste caso é interessante a explanação sobre a ciclagem de nutrientes e manutenção da floresta, por exemplo. Além disso, o livro cita ainda para esta região a degradação dos solos pela erosão hídrica em áreas onde a floresta é derrubada para implantação da agropecuária. Para a região Nordeste o livro aponta a questão do assoreamento do rio São Francisco pelo seu uso intensivo, e apresenta a definição de assoreamento como sendo o "acúmulo de detritos, transportados pelas águas, no leito de um rio". Nesse caso pode-se inserir na discussão questões como erosão hídrica que ocorre nas áreas agrícolas e que aportam sedimentos nos rios, sedimentos e riscos de contaminação da água, a erosão que ocorre nas margens dos 
rios desprotegidas de vegetação, e isso permite incluir questões como legislação ambiental e a importância da vegetação nas margens dos rios. O conteúdo pode ser aprofundado a respeito dos processos erosivos laminares e lineares, sendo estes últimos, através da formação de sulcos, ravinas e voçorocas, que são bastante conhecidos, pois visualmente são perceptíveis na paisagem. As discussões sobre a formação desses processos erosivos envolvem análises de diferentes elementos do meio físico e ação antrópica, corroborando assim para o desenvolvimento de raciocínios que requeiram integrar os solos no contexto do ambiente, da paisagem e ou do espaço geográfico. Sobre a região Sudeste, o livro aborda "os processos erosivos e a ação humana". Na região Sul o livro fala um pouco sobre a agricultura nesta região, mas em nenhum momento ele cita o solo. Na região Centro-Oeste o livro fala sobre a vegetação de cerrado e o solo, e sobre o solo e a produção agrícola.

A respeito do conteúdo abordado no livro de Geografia do Projeto Araribá para o $8^{\circ}$ ano do ensino fundamental (DANELLI, 2007c), referente ao PNLD de 2011 a 2013, seguem as seguintes observações:

- Unidade 3 (O continente americano): o solo é abordado de forma incipiente, apenas quando se fala da vegetação da América no tema 4 (Clima e vegetação da América). O livro cita a importância de se conhecer a vegetação original, pois ela é interdependente de outros elementos da natureza, como o solo. Quando o livro cita a vegetação Tundra, informa que o solo fica coberto por gelo em alguns meses do ano. Nas Florestas Tropicais e Equatoriais (Pluviais) o livro cita que "os solos de algumas Florestas Pluviais são pouco férteis, mas em sua parte superior apresentam uma camada muito rica de material orgânico conhecido como húmus".

- Unidade 4 (A população e a economia da América): no tema 2 (Atividades do setor primário na América) a questão da agricultura é citada na América Anglo-Saxônica e na América Latina, e o solo é referido especialmente na questão da correção da sua fertilidade. Embora pouco explorada a Ciência do Solo neste livro, nota-se a necessidade de seu conhecimento para explorar alguns conteúdos do solo como o húmus e sua formação, bem como seu efeito nas características físicas, químicas e biológicas do solo, assim como a necessidade de se abordar a ciclagem de nutrientes para manutenção das florestas. Há ainda a possibilidade de se discutir questões como o congelamento dos solos, situação que não ocorre no Brasil, por exemplo, mas é citado no livro quando se fala sobre a Tundra.

Em relação ao conteúdo abordado no livro de Geografia do Projeto Araribá para o $9^{\circ}$ ano do ensino fundamental (DANELLI, 2007d), referente ao PNLD de 2011 a 2013, em duas situações o solo poderia ser abordado, quando se fala sobre agricultura e sobre as questões ambientais, conforme segue:

- Unidade 2 (Globalização e organizações mundiais): no tema 2 (Globalização e meio ambiente), sobre os problemas ambientais do século $X X I$, não se pode deixar de relatar a degradação dos solos, bem como o desmatamento associado ao plantio de novas áreas agrícolas, tanto em solos adequados ou não para a agricultura. Abordagem semelhante pode ser feita no tema 1 (Quadro natural e problemas ambientais) da unidade 3 (O continente europeu). Quando se aborda a agricultura na Europa (tema 3 - A economia europeia, da unidade 3 - O continente europeu), na Ásia 
(tema 3 - A economia do continente asiático, da unidade 5 - O continente asiático), na África (tema 2 - A economia africana, da unidade 7 - O continente africano), também pode-se inserir na discussão a questão do solo, pois a agricultura, embora tenha relação direta com o clima, também tem no solo um agente influenciador em questões como tipo de cultura, irrigação e mecanização. No conteúdo do 9o ano, percebe-se que o solo pode ser trabalhado relacionando-o com a agricultura e com a sua degradação.

Em relação aos livros de Geografia do Projeto Araribá do $6^{\circ}$ ao $9^{\circ}$ ano do ensino fundamental referente ao PNLD de 2014 a 2016 (VEDOVATE, 2010a, b, c, d), percebeu-se que não houveram alterações significativas, principalmente nas questões relacionadas à abordagem do solo.

Avaliando a coleção de livro didático de Geografia adotada para o ensino fundamental (6ำ ao 9ano) nas escolas estaduais da cidade de Goiás, Costa e Mesquita (2010) identificaram que a abordagem sobre solos é muito restrita e insuficiente para que o aluno adquira as principais bases conceituais que envolvem o solo, e ainda identificaram erros conceituais, informações insuficientes nas figuras, que geram mais dúvidas, além das interpretações equivocadas quanto à leitura do mapa.

Buscando subsídios para auxiliar o ensino de solos nas escolas, Silva, Falcão e Sobrinho (2008) avaliando livros didáticos de Geografia do ensino fundamental II indicaram que os livros didáticos deveriam destinar capítulos específicos sobre novas metodologias desenvolvidas e destinadas ao entendimento do solo. Ressaltam também que os livros, por melhores que sejam, não devem ser utilizados como os únicos referenciais para fomentar a discussão, mas também outros recursos didáticos como trabalhos de campo, fotografias e a confecção de perfis esquemáticos.

Analisou-se também o livro "Geografia: O mundo em transição", para o ensino médio, de Vesentini (2010). Este é um livro com uma ampla abordagem sobre o Brasil, o qual apresenta itens específicos sobre o solo no capítulo 13 (Estrutura geológica, relevo e solos) da unidade III (Geofísica do Brasil): "Solos" e "Agricultura e solos no Brasil". No item "Solos" o autor apresenta alguns significados de solo, sua formação, características do solo de acordo com a região, fertilidade e erosão. No item "Agricultura e solos no Brasil", o autor desenvolve questões como sistemas de manejo do solo (revolvimento do solo e plantio direto), fertilidade e erosão. No item "Desertificação no Brasil", parte do capítulo 14 (Climas do Brasil), o autor cita este processo como consequência de uma "diminuição progressiva dos índices de umidade e no empobrecimento dos solos arenosos, que se tornam inviáveis para a agricultura", e cita ainda questões como o processo de arenização e seus impactos ambientais, sociais e econômicos, citando o Nordeste, em clima semiárido, e o Sudoeste do Rio Grande do Sul, como exemplos de regiões em processo de desertificação. Neste item o autor considera os conceitos de arenização e desertificação como sendo sinônimos, contudo, o que vem ocorrendo nestas regiões é considerado como arenização, já que o clima nestes locais não é condição para o processo de desertificação. Outra questão apontada no livro é o processo de arenização como consequência da ação humana, contudo, especialmente para o caso do Rio Grande do Sul, há linhas de estudo que afirmam ser este processo relacionado a uma condição natural do solo.

REVISTA GEONORTE, V.11, N.37, p.01-21, 2020.

DOI: 10.21170/geonorte.2020.V.11.N.37.01.21

(ISSN 2237 - 1419) 
Para auxiliar nessa discussão, alguns trabalhos podem ser utilizados como referência, como a obra "O Rio Grande do Sul descobre os seus "desertos" (SUERTEGARAY, 1990), onde a autora enriquece o debate sobre os "desertos" do Sudoeste do Rio Grande do Sul, através de discussões de natureza conceitual sobre desertos ou arenização, desertificação ou arenização; a polêmica sobre a gênese, distribuição e extensão dos núcleos de areia na região, se é um processo natural ou antrópico; e as estratégias para recuperação de áreas em avançado estágio de degradação, quanto ao uso de espécies autóctones ou exóticas.

No trabalho "Sítios arqueológicos e areais no sudoeste do Rio Grande do Sul" (BELLANCA; SUERTEGARAY, 2003) se discute a gênese dos areais como um processo natural na região sudoeste do Rio Grande do Sul. O processo de arenização, considerado um processo de degradação do solo, tem sido interpretado principalmente de origem antrópica, mas o trabalho o explica como um processo natural. Esta hipótese foi baseada nos fatos históricos e pré-históricos que comprovam a existência de páleo-indígenas coabitando com estes areais há, pelo menos, 3.500 A.P. As autoras demonstram que a hipótese de uma degradação destas, através da ação antrópica, pela monocultura e o superpastoreio, torna-se relativizada, no momento em que pode ser comprovada a existência destes areais já antes da ocupação europeia na região.

No artigo "Sobre a gênese da arenização no sudoeste do Rio Grande do Sul" (SUERTEGARAY et al., 2005), é explicado o processo de arenização que, segundo os autores, é o retrabalhamento de depósitos areníticos (pouco consolidados) ou arenosos (não consolidados), dificultando a fixação da vegetação nessas áreas devido à constante mobilidade dos sedimentos arenosos. Uma das explicações para esse processo é que as chuvas torrenciais retrabalham esses depósitos, pois os processos hídricos superficiais, particularmente o escoamento concentrado do tipo ravina ou voçoroca, expõem, transportam e depositam areia, dando origem a formação de areais que, em contato com o vento, tendem a uma constante remoção.

Diante do que tem sido relatado na literatura científica, o processo de arenização no Sudoeste do Rio Grande do Sul parece ser natural devido a fragilidade dos solos nesta região, porém, é intensificado pela ação do homem, especialmente pelo uso do solo para agricultura e pecuária.

A partir desta avaliação dos eixos temáticos em Ciência do Solo nos PCNs e nos livros didáticos, percebe-se a necessidade de formação dos professores em Geografia para trabalhar de forma adequada conteúdos de Ciência do Solo nas escolas. Também se observou a necessidade de revisão de alguns termos ligados a Ciência do Solo publicados nos livros didáticos.

\section{Conhecimento em Ciência do Solo dos licenciandos em Geografia (UFPel)}

Os questionários foram respondidos por 35 alunos do curso de Licenciatura em Geografia, sendo que destes alunos, também cursa Bacharelado em Geografia. 
A idade dos alunos variou entre 21 e 50 anos, predominando discentes com idades entre 20 a 34 anos (63\%) (Figura 01). Destes, 19 pessoas são do sexo masculino e 16 do sexo feminino.

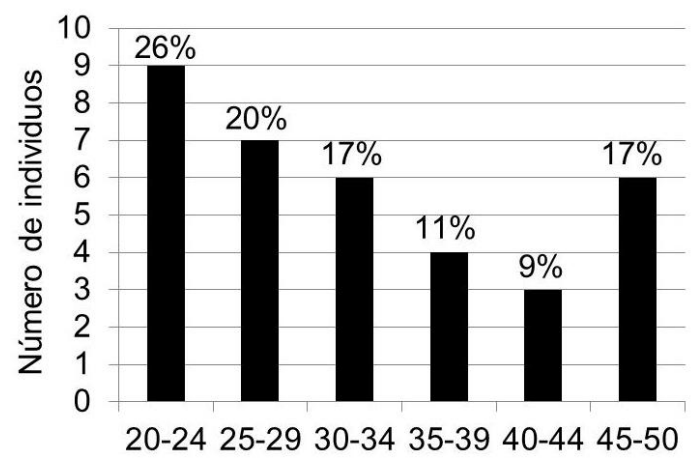

Faixa etária

Figura 01. Faixa etária dos alunos que responderam o questionário. A porcentagem foi calculada em relação ao total de 35 alunos que responderam o questionário. Fonte: Autores.

$\mathrm{O}$ ano de ingresso no curso de Licenciatura abrangeu de 2006 a 2014, sendo um aluno ingressante em 2006, e um em 2007, nenhum ingressante em 2008, dois ingressantes em 2009, três ingressantes em 2010, seis ingressantes em 2011, doze em 2012, seis ingressantes em 2013 e um em 2014. Três alunos não informaram o ano de ingresso, e o aluno que também cursa Bacharelado, ingressou neste em 2009.

Questionados sobre "O que é solo?", seis alunos (17\%) não responderam a questão, enquanto dez alunos (29\%) definiram solo como camada ou cobertura superficial ou externa da crosta terrestre; material ou camada que cobre a superfície terrestre, e outros dois alunos incluíram na resposta anterior o solo como sustento a vários tipos de vegetação; onde se desenvolve atividades agrícolas e extrativismo. Outros três alunos ( $9 \%$ ) definiram solo como fragmentos de rochas; rocha em decomposição.

Outras definições de solo foram apontadas pelos alunos como: local ou porção composto principalmente por resíduos orgânicos e minerais; um conjunto de matéria orgânica e sedimentos; material resultante de um processo de decomposição mineralógica; partículas rochosas, de granulometrias variadas e composição mineral também distintas; material em superfície, detentor de características arenosas, argilosas e outras, dependendo do material rochoso que impõe o seu entorno; resultado da transformação física e química das rochas que somado com material orgânico oferece condições para ser usado em diversas áreas com diversas funções.

Algumas respostas apresentaram a dificuldade dos alunos em definir o solo: partículas de terra e minerais; camada que reveste o relevo da terra; matéria orgânica acumulada; terra onde se fixam os vegetais; sedimentos acomodados na crosta terrestre; concentração de detritos compactados ricos em minerais; camada do relevo terrestre; a terra e o seu uso. Em algumas respostas ficou evidente a dificuldade em diferenciar solo e terra.

O "Vocabulário de Ciência do solo" apresenta as seguintes definições para solo: 
"(1) Material mineral e/ou orgânico inconsolidado na superfície da terra que serve como um meio natural para o crescimento e desenvolvimento das plantas terrestres. (2) Matéria mineral não consolidada, na superfície da terra, que foi sujeita e influenciada por fatores genéticos e ambientais do material de origem, clima (incluindo efeitos de umidade e temperatura), macro e microrganismos, e topografia, todos atuando durante um período e produzindo um produto - solo, o qual difere do material do qual ele é derivado em muitas propriedades e características físicas, químicas, mineralógicas, biológicas e morfológicas." (CURI et al., 1993, p. 74).

Enquanto terra é definida como:

\begin{abstract}
"Meio ambiente total (natural e cultural) dentro do qual a produção tem lugar; um termo mais amplo que solo. Em adição a solo, seus atributos incluem outras condições físicas, tais como, depósitos minerais, clima e suprimento de água; localização em relação aos centros de comércio, populações, e outras terras: como definido anteriormente, mas sem critérios econômicos ou culturais, especialmente na expressão "terra natural"; como um sinônimo para "solo"; para a superfície sólida da "terra"; e também para formações superficiais terrestres, especialmente na expressão geomorfológica "paisagem"." (CURI et al., 1993, p. 80).
\end{abstract}

Sobre "Como ocorre a formação do solo?", dois alunos (6\%) não responderam, enquanto 14 alunos (40\%) apontaram como o desgaste e/ou decomposição e/ou fragmentação e/ou intemperismo e/ou erosão e/ou transformação das rochas. Dois alunos (6\%) indicaram que o solo é formado a partir da sedimentação das rochas. Outras respostas também foram apontadas como: através dos processos endógenos e exógenos; resulta do processo de decomposição física, química e biológica dos materiais minerais que o constituem; pela erosão das rochas e acumulação no decorrer do tempo geológico; ocorre do movimento das placas tectônicas, e posteriormente pela influência do intemperismo físico e químico; ocorre por deposição de sedimentos, de materiais trazidos por erosão ou por intemperismo; resultante de processos de sedimentação e erosão das rochas, que desagregam e vão em direção ao ponto mais baixo, e eventos tectônicos ocorridos na área também são responsáveis pela formação do solo; é o resultado da transformação física e química das rochas que somado com material orgânico oferece condições para ser usado em diversas áreas com diversas funções; se dá através do deslocamento de sedimentos que se desprenderam das rochas por intemperismo e transportado por água da chuva ou vento para um local mais abaixo, estes sedimentos de vários tipos de rochas vão formando o solo com as características desta rocha; ação de intemperismo, movimento tectônico, falhas e dobras, vulcanismo sobre rochas.

Outras respostas demonstraram a dificuldade dos alunos em apontar como ocorre a formação do solo: compactação de matéria orgânica e ou sedimentos; desgaste, erosão dos planaltos; deposição com a ocorrência da chuva e ventos que levam partículas diversas de um lugar para outro; a partir de um conjunto de sedimentos; através da concentração de diversos elementos que se acumulam dos mais variados eventos naturais e não naturais; ocorre com o acúmulo de materiais. 
Algumas respostas se distanciaram um pouco da pergunta, por exemplo: o solo é formado por diversas camadas, desde a rocha até a parte da matéria orgânica; aglomeração de minerais.

Sobre "O que é erosão?", apenas dois alunos (6\%) não responderam, enquanto 15 alunos (43\%) indicaram erosão como sendo a degradação e/ou desgaste do solo e/ou da rocha. Outras respostas também foram relacionadas, algumas com certa dificuldade em definir erosão: é a "deslização" que ocorre através do intemperismo; é o processo de deslocamento que uma rocha ou solo sofre com efeito da água, vento ou sol; é o processo de desgaste e transporte de sedimentos; é o processo de intemperismo químico e físico; processo de desgaste deste solo, onde acaba sofrendo com mais intensidade diversos processos de desgaste; degradação do solo; é o desgaste de rochas ou solos causando fendas e sedimentação; arraste de camadas do solo através dos ventos e das chuvas; é o desgaste físico, químico e biológico que o solo sofre alterando assim suas características; processo de intemperismo físico, químico e biológico, ocorridos na natureza; perda de nutrientes do solo; processo de desagregação das rochas; fissuras que são abertas no solo; é a "deteriorização" de formações rochosas (de variados tipos) através do intemperismo químico e físico; são fragmentos que se deslocam por motivos como água, vento, pressão; carreamento da porção superficial de solo por ação da água, vento e/ou degelo; é o mau uso da terra.

Outras respostas apresentam maior dificuldade em definir erosão: processo decorrente da devastação do solo; é o desmoronamento do solo a partir das intempéries; é quando o solo começa a erodir por consequência de vários fatores, entre eles climáticos (vento, chuva); através das forças internas e externas da natureza, por exemplo, vulcanismo, vento, chuva, ação antrópica, há o desgaste de rochas.

Alguns termos utilizados, como "deslização", podem ter influência da formação inicial dos alunos nos ensinos fundamental e médio.

Sobre "O que é plantio direto, cultivo mínimo e plantio convencional?", 16 alunos (46\%) não responderam, enquanto responderam corretamente o que é plantio direto nove alunos (26\%) e cinco alunos (14\%) o que é plantio convencional, e nenhum respondeu corretamente sobre cultivo mínimo. Dentre as definições de plantio direto, algumas foram: quando não há preparo da terra; plantio sem preparo do solo; ocorre da implantação de determinado cultivo sem manejo do solo; cultivo sem grandes modificações e preparações do espaço; o cultivo (preparo) da terra é feito sem a utilização dos processos mecânicos de aragem, etc., ou seja, a plantação é feita no solo como ele está. Dentre as definições de plantio convencional, pode-se citar: quando há uma preparação prévia para o cultivo e é anualmente; segue uma sequência prévia de preparo, adubação química ou orgânica; aquele em que imperam técnicas comuns de preparo, plantio, pousio e rotação de culturas; todo o processo de preparação da terra para o cultivo mecanizado.

Sobre “O que é terraceamento e curva de nível?", onze alunos ( $31 \%$ ) não responderam a questão, e dentre aqueles que responderam, nenhum definiu corretamente terraceamento, enquanto sete alunos (20\%) responderam que curva de nível é a altitude do solo ou do relevo ou do terreno. Outras definições de curva de 
nível também foram citadas como, por exemplo: responsável por demonstrar os diferentes níveis do solo; forma como as diferentes altitudes e declividades são representadas; são os pontos comuns altimétricos em relação à planície; declive do solo; desnivelamento do solo; são linhas imaginárias utilizadas para medir a altitude topográfica; processo utilizado para reter a força das águas em plantações; a forma correta do uso do solo através das curvas de nível.

Cabe salientar que o questionamento sobre curva de nível tinha um enfoque de manejo e conservação do solo e da água, mas como no questionário não estava indicado este viés, as respostas foram direcionadas para o conceito cartográfico, trabalhado na disciplina de Cartografia Geral, no segundo semestre do curso de Licenciatura.

Curva de nível pode ser definida como:

"(1) Linha imaginária sobre a superfície da terra unindo pontos de mesma cota. (2) Linha que se traça em mapas para assinalar os locais de mesmo nível. (3) Uma série de linhas ou curvas em nível representando a topografia do terreno." (Curi et al., 1993, p.25).

Enquanto terraço pode ser definido como:

\begin{abstract}
“(1) Planície nivelada, normalmente estreita, que margeia um rio, lago ou mar. Pode haver mais de um terraço, a diferentes níveis, margeando um rio. (2) Série de diques e canais, construídos na direção das curvas de nível, com a finalidade de reter ou escoar lentamente as águas, minimizando a erosão. A profundidade do canal, a largura do camalhão do terraço e os espaçamentos dos terraços no campo são variáveis conforme os tipos de solo, sistemas de culturas, condições climáticas e outros fatores." (Curi et al., 1993, p.81).
\end{abstract}

Questionados sobre “O que é perfil de solo? E horizontes do solo?”, 20 alunos $(57 \%)$ não responderam, enquanto alguns responderam de forma equivocada. Algumas definições foram: perfil são características do solo, e horizontes são as camadas do mesmo; perfil do solo refere-se as divisões das camadas que compõem o solo; perfil do solo - tipo de solo, horizonte - camadas de solo. Houveram algumas definições equivocadas ou que apresentaram dificuldade nas definições, como por exemplo: horizonte é o nível de solo $A, B, C, E$, e serve para verificar a origem do solo; perfil: qualidade do solo, horizonte: tamanho do solo; perfil: corresponde a sua gênese, exemplo: argiloso; perfil é a composição química do solo; filas de solo, discordância erosiva; perfil do solo são camadas caracterizadas por algum tipo de sedimento; as diferenças de altitude, as "ondulações" no solo, como ele se apresenta; perfil de solo é a representação gráfica dos horizontes do solo e horizontes do solo é a composição orgânica e mineral; são as várias camadas de diferentes períodos do solo; amostra para identificação de tipo, volume para identificação do perfil; perfil: A - camada superficial, B - camada redutiva, C - camada intermediária; D - camada rochosa.

Se os alunos haviam cursado alguma(s) disciplina(s) específica(s) sobre solos, 19 alunos (54\%) responderam não, enquanto doze alunos (34\%) apontaram Geologia e sete $(20 \%)$ responderam Geomorfologia, embora para ambas as disciplinas os alunos indicaram que havia pouco conteúdo sobre solos ou apenas alguns aspectos básicos. 
No projeto pedagógico do curso de Licenciatura em Geografia da UFPel, versão de outubro/2006, disponível na "home page" do curso na internet (http://wp.ufpel.edu.br/geografia), os assuntos que podem estar associados ao ensino de solos na disciplina de Geologia I são fatores e processos de formação do solo; propriedades físicas e químicas do solo; classificações taxonômicas e utilitárias dos solos; análise regional do uso da terra a partir do mapeamento geológico e pedológico. $\mathrm{Na}$ disciplina de Geomorfologia, os assuntos associados ao ensino de solos podemse citar: agentes e processos geomorfológicos: Processos endógenos e exógenos na formação do relevo; formas do relevo e processos erosivos.

Questionados sobre a "importância da(s) disciplina(s) de solos na sua formação?", um aluno não respondeu enquanto 34 alunos (97\%) consideram importante, com algumas justificativas: é extremamente importante, pois como Geógrafo não temos formação adequada; ter um maior entendimento do uso do solo e da ocupação do mesmo; é muito importante, pois é uma ciência que está atrelada a Geografia; é importante justamente na compreensão não só de um movimento constante deste ciclo geológico, mas principalmente na sua importância na produção de alimentos; devemos ter um conhecimento de tudo que pudermos no que diz respeito ao nosso objeto de estudo que é a Geografia; tal disciplina é de extrema importância para a compreensão da dinâmica geoespacial em geral, tais como: formação da terra, sistemas de produção agrícola, distribuição de renda, etc.; de grande relevância, pois o Geógrafo, para poder compreender dados processos e fenômenos, necessita desse tipo de conhecimento específico; é importante principalmente porque este conteúdo também é ensinado pelos professores na educação básica e nesse sentido seria de suma importância ter maior proximidade com uma disciplina de solos; de grande importância, pois precisamos conhecer para poder ensinar aos alunos; no meu caso é importante porque sou do interior; possui muita importância, pois a Geografia também aborda a questão dos solos; é importante termos disciplinas relacionadas a esta temática, para conhecermos mais a temática e para ensinarmos os conteúdos relacionados ao mesmo para os alunos; entender a importância da conservação, manutenção e utilização correta do solo; em vista de estar cursando Licenciatura em Geografia seria importante para domínio de conteúdo e para propiciar o entendimento mais aprofundado de algo que é de extrema relevância as práticas sociais; para entender melhor a formação geológica e a geografia da paisagem; total importância tendo em vista que as riquezas em sua grande maioria são resultantes da forma como o solo é explorado para a construção civil etc; creio que seria importante habilitarmos em mais um ramo do conhecimento.

Sobre a questão: "Você se sente preparado para trabalhar com o tema Ciência do Solo?", apenas um aluno (3\%) afirmou estar preparado para trabalhar com o tema, enquanto 34 alunos (97\%) responderam "não", com algumas justificativas: não pois tive poucos ensinamentos sobre solo no curso de Geografia; teria que aprofundar o assunto para ministrar aulas; não, de forma alguma, o curso de licenciatura não oferece uma cadeira para que o conhecimento seja aprofundado.

Questionados se "Caso não esteja preparado para trabalhar com o tema Ciência do Solo, o que você entende que seria necessário no curso para prepará-lo para esta área?", três alunos não responderam, enquanto outros alunos fizeram sugestões

REVISTA GEONORTE, V.11, N.37, p.01-21, 2020.

DOI: 10.21170/geonorte.2020.V.11.N.37.01.21

(ISSN 2237 - 1419) 
como: uma a três disciplinas na área foi sugerida por 18 alunos; um aluno sugeriu incluir o tema em outras disciplinas; cinco apontaram a necessidade de atividades práticas ou externas ou laboratórios; e quatro apontaram a necessidade de professores qualificados e comprometidos. Outras questões foram apontadas como um investimento e atenção maior na formação de professores; é necessário haver mais disciplinas relacionadas à Geografia Física; não é uma ciência para um semestre, na minha opinião exige um segmento mais amplo; acredito que seja mais importante para o curso de bacharelado, uma vez que tornaria o curso de licenciatura muito extenso; acho que especificamente para trabalhar com o tema não seria o curso que deveria preocupar-se e sim o acadêmico em busca desta cadeira como optativa.

Considerando os eixos temáticos em Ciência do Solo nos PCNs e nos livros didáticos e, a partir das respostas dos questionários, há necessidade de se trabalhar de forma mais intensa os conteúdos da Ciência do Solo no curso de Licenciatura em Geografia.

No curso de Bacharelado em Geografia da UFPel, há a disciplina obrigatória Pedologia, e contempla em sua ementa os seguintes pontos: abordagens conceituais de solo e Pedologia; fundamentos da gênese do solo; constituintes do solo; morfologia dos solos; distribuição dos solos em diferentes escalas. Talvez esta disciplina poderia suprir minimamente a demanda dos alunos da Licenciatura em Geografia da UFPel.

\section{Universidades com curso de Geografia no Rio Grande do Sul}

A partir da "home page" do Ministério da Educação (2016) (http://emec.mec.gov.br/) foram identificadas 22 instituições de ensino superior no Rio Grande do Sul que possuem o curso de graduação em Geografia, seja Licenciatura e/ou Bacharelado. Destas, cinco são universidades públicas (Universidade Federal do Rio GrandeFURG, Universidade Federal do Rio Grande do Sul-UFRGS, Universidade Federal de Santa Maria-UFSM, Universidade Federal de Pelotas-UFPel e Universidade Federal da Fronteira Sul-UFFS) e 17 são particulares.

Algumas universidades possuem o curso de Licenciatura e Bacharelado, sendo oferecidos no Estado sete cursos de Bacharelado e 25 de Licenciatura, sendo que dos cursos de Licenciatura, 11 são a distância e 14 são presenciais. Chama a atenção o fato de que na "home page" do Ministério da Educação (2016) a UFSM não oferece o curso de Bacharelado, mas na "home page" do curso de Geografia da UFSM (http://w3.ufsm.br/ccne/index.php/graduacao/12-geografia-bacharelado-e-

licenciatura) são apresentados os cursos de Licenciatura e Bacharelado; e na "home page" do Ministério da Educação (2016) consta o curso de Licenciatura da UFRGS duas vezes.

Estes dados mostram o grande número e predomínio dos cursos de Licenciatura em relação ao Bacharelado, e enfatiza a necessidade de uma formação adequada dos futuros professores em Geografia, incluindo assuntos pertinentes ao profissional, dada a amplitude de sua formação e necessidade de inter-relação entre os assuntos e visão abrangente e sistêmica, e isso inclui o ensino de solos. Também chama a atenção o grande número de cursos de Licenciatura a distância em relação aos presenciais. 
Dos cursos de Geografia verificados, 23 tinham disponível em sua "home page" informações sobre as disciplinas ofertadas. Destes 23 cursos, nove oferecem alguma disciplina na área de Ciência do Solo, sendo que destes, três cursos oferecem a disciplina como optativa, o que corresponde a dizer que cerca de $19 \%$ dos cursos de Geografia, dentre os 32 cadastrados, oferecem alguma disciplina de solos como obrigatória, e aproximadamente $10 \%$ dos cursos a oferecem como optativa.

É baixa a porcentagem de cursos que oferecem a disciplina de solos, considerando a pertinência do ensino de solos para a Geografia, pois é um tema que pode interrelacionar com vários outros assuntos amplamente estudados pela Geografia como por exemplo, relevo, bacia hidrográfica, clima, vegetação, geologia, questões econômicas e sociais, uso e ocupação das terras e do espaço, processo erosivo, meio ambiente e impactos ambientais.

Uma crítica deve ser feita a disponibilização de informações sobre os cursos nas "home pages" das instituições. É inaceitável nos dias atuais, com o grande acesso da população à internet, que não seja disponibilizado o projeto pedagógico ou informações mais consistentes sobre os cursos.

A seguir serão apresentados detalhes das disciplinas da área de Ciência do Solo ofertadas nos cursos.

Nos cursos de Licenciatura e Bacharelado em Geografia da Universidade Federal do Rio Grande (FURG) (http://www.furg.br/), a disciplina de "Solos" é ofertada como optativa contemplando uma carga horária de 45 horas, equivalente a 3 créditos, abordando os seguintes assuntos: origem e formação dos solos; mineralogia dos solos; química dos solos; física dos solos e classificação dos solos.

No Centro Universitário Franciscano (UNIFRA) (http://wwww.unifra.br/site), no curso de Licenciatura a disciplina "Solos e ambiente" é oferecida como optativa, com uma carga horária de 34 horas, equivalente a 2 créditos. Não foi possível verificar os assuntos abordados devido a ementa da disciplina não estar disponível.

$\mathrm{Na}$ Universidade Federal de Santa Maria (UFSM) (http://w3.ufsm.br/ccne/index.php/graduacao/12-geografia-bacharelado-elicenciatura), no curso de Licenciatura e Bacharelado é oferecida uma disciplina obrigatória denominada "Geografia e solos", com uma carga horária teórica de 45 horas e 15 horas de prática, totalizando 60 horas e correspondente a 3 créditos.

A "home page" dos cursos não disponibilizou a ementa da disciplina, contudo, seus objetivos são "identificar, compreender e analisar a cobertura pedológica frente aos fatores de formação e propriedades do solo face a compartimentação e formas de relevo, estrutura da paisagem e funcionamento dos suportes ecológicos". Além desta disciplina obrigatória, os cursos ainda indicam disciplinas complementares de graduação, geralmente ofertadas por outros departamentos da universidade. Dentre estas disciplinas citam-se: "Manejo de bacias hidrográficas", com 15 horas teóricas e 30 horas práticas, perfazendo um total de 45 horas.

Os objetivos da disciplina são "planejar a recuperação de bacias hidrográficas mediante a diminuição da erosão, controle de enxurradas, balanço hídrico visando a melhorar a qualidade da água", e em sua ementa consta "introdução ao estudo de 
manejo de bacias hidrográficas, erosão e desmoronamento, torrentes, plano de ordenamento para uma bacia hidrográfica". "Manejo e conservação do solo", com 15 horas teóricas e 30 horas práticas, perfazendo um total de 45 horas. Os objetivos da disciplina são "identificar os processos erosivos e conhecer as principais práticas de controle visando o aproveitamento racional do solo e dos fertilizantes". "Manejo e fertilidade do solo", com 45 horas de aula teórica e 30 horas práticas, totalizando 75 horas. Os objetivos da disciplina são "conhecer a biogeoquímica dos nutrientes essenciais para a produção de forrageiras e avaliar a sua disponibilidade no solo; identificar os processos erosivos e conhecer as práticas de controle, visando o aproveitamento racional do solo e dos fertilizantes". "Fertilidade e conservação do solo", com 45 horas de aula teórica e 30 horas práticas, totalizando 75 horas. Os objetivos da disciplina são identificar a reação do solo, diferenciar e avaliar a disponibilidade dos nutrientes essenciais à nutrição vegetal e distinguir os efeitos da erosão, visando ao aproveitamento racional do solo e dos fertilizantes. Na ementa consta "introdução à fertilidade e conservação do solo; elementos essenciais à nutrição vegetal; reação do solo; transformações biológicas no solo; macronutrientes principais à nutrição vegetal; macronutrientes secundários à nutrição vegetal; micronutrientes essenciais à nutrição vegetal; avaliação da fertilidade do solo e recomendação de fertilizantes; erosão do solo; práticas conservacionistas; sistemas de cultivo convencional".

$\mathrm{Na}$ Universidade Federal de Pelotas (UFPel) (http://wp.ufpel.edu.br/geografia/projetopedagogico/) o curso de Bacharelado possui uma disciplina obrigatória denominada "Pedologia", com 34 horas totais, sendo 17 horas teóricas e 17 práticas, ofertada no quarto semestre do curso. Sua ementa compreende "abordagens conceituais de solo e pedologia; fundamentos da gênese do solo; constituintes do solo; morfologia dos solos; distribuição dos solos em diferentes escalas".

No Centro Universitário de Maringá

(https://www.unicesumar.edu.br/ead/cursos-graduacao/geografia/) é ofertada a disciplina obrigatória "Geologia e pedologia" no nono módulo do curso de Licenciatura na modalidade a distância. A "home page" não disponibilizou a ementa da disciplina.

$\mathrm{Na}$ Faculdade Educacional da Lapa (FAEL) (http://fael.edu.br/cursos/graduacao/geografia/) a disciplina obrigatória "Pedologia" é oferecida no quinto semestre e possui uma carga horária total de 100 horas, no curso de Licenciatura na modalidade a distância. A "home page" do curso não disponibilizou a ementa da disciplina.

O Centro Universitário Internacional (UNINTER) (http://www.uninter.com/graduacaoead/cursos/licenciaturas/geografia) oferece a disciplina obrigatória de "Geologia e pedologia", com carga horária de 80 horas, no curso de Licenciatura na modalidade a distância. A "home page" do curso não disponibilizou a ementa da disciplina.

No curso de Licenciatura da Universidade Federal da Fronteira Sul (UFFS) (http://www.uffs.edu.br/index.php?option=com_content\&view=article\&id=1156\&ltemid =1732), Campus Chapecó, a disciplina obrigatória "Geografia dos solos" é oferecida no quarto semestre com 60 horas total, correspondente a 4 créditos. Cabe salientar que o currículo foi reformulado em 2014, pois antes (2010) não havia a disciplina. A 
ementa compreende "o solo enquanto recurso natural; pedogênese e fatores de formação do solo; inter-relações entre morfogênese e pedogênese; processos pedogenéticos; constituintes do solo; química e física do solo; classificação e distribuição das principais classes pedológicas no Brasil; erosão e fatores associados; conservação do solo".

Apesar de poucos cursos disponibilizarem na internet seus projetos pedagógicos ou ementas ou planos de ensino, verifica-se que a abordagem das disciplinas obrigatórias na área de solos é abrangente, contemplando vários aspectos da Ciência do Solo como: fatores de formação do solo, mineralogia, morfologia, classificação do solo, distribuição dos solos, física do solo, fertilidade, erosão e conservação do solo.

\section{CONSIDERAÇÕES FINAIS}

Os PCNs e os livros didáticos para o ensino fundamental e médio abordam o conhecimento sobre solos em seus mais variados aspectos, explicitamente questões como erosão, uso e manejo do solo, degradação do solo, fertilidade e o processo de arenização. Contudo, esta abordagem é pequena e limitada, e não explora a interdisciplinaridade e as relações do solo com outros fatores da natureza, e com questões sociais e econômicas.

O número de cursos de Licenciatura em Geografia no Rio Grande do Sul é significativamente superior aos de Bacharelado, e poucos cursos possuem em seu currículo disciplinas na área de Ciência do Solo. Dentre as disciplinas na área, os assuntos abordados incluem fatores de formação do solo, mineralogia, morfologia, classificação do solo, distribuição dos solos, física do solo, fertilidade, erosão e conservação do solo.

Os PCNs para a Geografia e os livros didáticos contemplam o conhecimento em Ciência do Solo, contudo, de modo geral os cursos de Geografia não fornecem subsídios suficientes para esta abordagem em sala de aula. Indica-se, assim, que os cursos de Licenciatura em Geografia reformulem seus projetos pedagógicos, especialmente quanto à necessidade de inserção de disciplinas relacionadas à área da Ciência do Solo.

Sugere-se que a elaboração de livros didáticos seja realizada a partir da colaboração entre os autores e as instituições de ensino superior, especificamente com grupos de trabalho relacionados aos assuntos abordados nos livros.

O conhecimento dos alunos graduandos em Licenciatura em Geografia da UFPel é pouco abrangente para trabalhar o ensino de solos no ensino fundamental e médio, havendo uma demanda dos próprios alunos para a inclusão no curso de uma ou mais disciplinas específicas sobre solos. Como forma a suprir minimamente esta demanda, bem como incluir na formação destes alunos uma maior base nesta área, sugere-se que o curso recomende aos alunos cursarem uma ou mais disciplinas na área de solos no curso de Bacharelado em Geografia ou em outros cursos da universidade que possuem esta disciplina no currículo. Esta recomendação também é válida para os 
demais cursos de Licenciatura em Geografia do Brasil que não possuem disciplinas na área de Ciência do Solo em seus currículos.

\section{REFERÊNCIAS}

BELLANCA, E. T.; SUERTEGARAY, D. M. A. Sítios arqueológicos e areais no sudoeste do Rio Grande do Sul. Mercator - Revista de Geografia da UFC, FortalezaCE, n. 4, p. 99-114, 2003.

BRASIL. SECRETARIA DE EDUCAÇÃO FUNDAMENTAL. Parâmetros curriculares nacionais: geografia /Secretaria de Educação Fundamental. Brasília: MEC/SEF, 1998.

COSTA, A. A.; MESQUITA, N. L. Ensino de Geografia e solos: o livro didático nesse cenário. In: SEMINÁRIO DE INICIAÇÃO CIENTÍFICA, JORNADA DE PESQUISA E PÓS-GRADUAÇÃO, 8., 5., Goiás, 2010, Anais... Goiás, 2010. 16p.

CURI, N.; LARACH, J. O. I.; KÄMPAF, N.; MONIZ, A. C.; FONTES, L. E. F.

Vocabulário de Ciência do Solo. Campinas: Sociedade Brasileira de Ciência do Solo, 1993. 90p.

DANELLI, S. C. S. (editora responsável). Projeto Araribá: Geografia - $6^{\circ}$ ano. 2. ed. São Paulo: Moderna, 2007a. (PNLD 2011, 2012, 2013)

DANELLI, S. C. S. (editora responsável). Projeto Araribá: Geografia - 70 ano. 2. ed. São Paulo: Moderna, 2007b. (PNLD 2011, 2012, 2013)

DANELLI, S. C. S. (editora responsável). Projeto Araribá: Geografia - $8^{\circ}$ ano. 2. ed. São Paulo: Moderna, 2007c. (PNLD 2011, 2012, 2013)

DANELLI, S. C. S. (editora responsável). Projeto Araribá: Geografia - $9^{\circ}$ ano. 2. ed. São Paulo: Moderna, 2007d. (PNLD 2011, 2012, 2013)

LIMA, M. R. O solo no ensino de ciências no nível fundamental. Ciência \& Educação, Bauru-SP, v. 11, n. 3, p. 383-394, 2005.

MINISTÉRIO DA EDUCAÇÃO. Instituições de ensino superior e cursos cadastrados. Disponível em: <http://emec.mec.gov.br/>. Acesso em: 4 out. 2016.

MORAIS, E. M. B. de. O ensino das temáticas físico-naturais na Geografia escolar. Tese (Doutorado em Geografia) - Faculdade de Filosofia, Letras e Ciências Humanas, Universidade de São Paulo, São Paulo-SP, 2011. 309 f.

OLIVEIRA, D. O conceito de solo sob o olhar de crianças do Ensino Fundamental em escolas de São Paulo-SP. Ciência e Natura, Santa Maria-RS, v. 36, edição especial, p. 210-214, 2014. 
SACRAMENTO, A. C. R.; FALCONI, S. Educação geográfica e ensino de solos: uma experiência em sala de aula. Revista Geográfica de América Central, Costa Rica, número especial EGAL, p.1-15, 2011.

SEVERINO, A. J. Metodologia do trabalho científico. 23. ed. ver. e atual. São Paulo: Cortez, 2007.

SILVA, A.C.; RIBEIRO, A.L.S. A disciplina pedologia ministrada nos cursos de geografia em diversas cidades maranhenses por meio do PROCAD. Geografia, Londrina-PR, v. 13, n. 1, p. 143-150, 2004.

SILVA, C. S.; FALCÃO, C. L. C.; SOBRINHO, J. F. O ensino do solo no livro didático de Geografia. Revista Homem, Espaço e Tempo, n. 1, p. 101-111, 2008.

SUERTEGARAY, D.M.A. O Rio Grande do Sul descobre os seus "desertos". Ciência \& Ambiente, Santa Maria-RS, v. 1, n. 1, p. 33-52, 1990.

SUERTEGARAY, D. M. A.; VERDUM, R.; BELLANCA, E. T.; UAGODA, R. S. Sobre a gênese da arenização no sudoeste do Rio Grande do Sul. Terra Livre, São PauloSP, v. 1, n. 24, p. 135-150, 2005.

VAZ, A. J.; ANJOS, R. M. Como trabalhar a educação ambiental através do estudo do solo em aulas de Geografia. In: ENCONTRO NACIONAL DE PRÁTICA DE ENSINO EM GEOGRAFIA, 10, 2009, Porto Alegre. Anais... Porto Alegre, 2009. 14p.

VEDOVATE, F. C. (editor responsável). Projeto Araribá: Geografia - $6^{\circ}$ ano. 2. ed. São Paulo: Moderna, 2010a. (PNLD 2014, 2015, 2016)

VEDOVATE, F. C. (editor responsável). Projeto Araribá: Geografia - 70 ano. 2. ed. São Paulo: Moderna, 2010b. (PNLD 2014, 2015, 2016)

VEDOVATE, F. C. (editor responsável). Projeto Araribá: Geografia - $8^{\circ}$ ano. 2. ed. São Paulo: Moderna, 2010c. (PNLD 2014, 2015, 2016)

VEDOVATE, F. C. (editor responsável). Projeto Araribá: Geografia - $9^{\circ}$ ano. 2. ed. São Paulo: Moderna, 2010d. (PNLD 2014, 2015, 2016)

VESENTINI, J. W. Geografia: O mundo em transição: Ensino médio. Volume 3. São Paulo: Ática, 2010. 